\title{
Light interception and its relation to structural differences in three Australian rainforest canopies
}

\author{
M. D. LOWMAN \\ Zoology Department, University of Nen' \\ England, Armidale, NSW 2351, Australia
}

\section{Abstract}

Relative differences in the seasonality of light penetrating the canopies of three Australian rainforests were measured directly with a quantum meter and indirectly using hemispherical photographs. The mossy microphyll fern forest had higher incident light levels (100-200 $\mu$ Einstein $m^{-2}$ per s) and more sky visible (21.8\%) at ground level than the simple $\left(5-20 \mu\right.$ Einstein $m^{-2}$ per $s$ with $11.2 \%$ skylight $)$ and complex $\left(5-10 \mu\right.$ Einstein $m^{-2}$ per $s$ with $10.8 \%$ skylight) notophyll vine forests. There were no significant changes in amounts of sky visible through the canopy over time (10 months) for any canopy, despite the fact that leaf-fall was a seasonal event. Profile diagrams were constructed at each site to illustrate the depth and stratification of the canopy, and the differences in these structural features were related to the variation in light attenuation. Ecological aspects of light interception through rainforest canopies are discussed, including tree branch growth patterns and leafing phenologies, and seedling regeneration on the forest floor.

\section{Introduction}

Light penetration through a fores1 canopy maintains understorey vegetation and determines the degree of suppression or vigour of its growth. In deciduous forests, the annual loss of leaves from the canopy results in a large seasonal change in light influx to the forest floor (Horn 1971), and many herbaceous understorey species leaf out early in the spring, before the new canopy in the overstorey flushes and intercepts light (Jackson 1966).

In evergreen rainforests, a complete seasonal loss of canopy foliage never occurs; leaf-fall is continuous throughout the year. Within several Australian rainforests, there are distinct seasonal peaks in leaf-fall (Webb et al. 1969), without concurrent replacement of canopy by leaf emergence (Brasell et al. 1980; Lowman 1982). In particular, the cool temperate rainforest sheds approximately half of its canopy during autumn, but this is not replaced until the following spring. Both warm temperate and subtropical rainforests exhibit less significant (but nonetheless pronounced) leaf-falls in early spring, with new leaf replacement occurring gradually throughout late spring and summer.

Because these rainforests exhibit degrees of seasonality in leaf-fall and leaf replacement, it is postulated that the amount of sky visible from the forest floor up through the canopy will exhibit temporal fluctuations relative to the proportion of leaf loss. In addition, the incidence of light through the canopy is predicted to vary according to canopy density and structure. To examine these hypotheses, two types of light measurements were conducted in three rainforest formations. First, hemispherical photographs (Evans \& Coombe 1959: Anderson 1964; Horn 1971) were taken monthly during 1 year to indicate the relative changes in the leafiness of the canopy by measuring the proportion of sky visible at ground level, and to indicate the canopy structure by comparing the amounts of sun flecks with light gaps. Second, direct light readings were made at different levels within the three canopies to compare available light for leaves under different canopy conditions. Profile diagrams were constructed to illustrate the structural features of each canopy, and were examined in relation to light interception through the canopies. Light was defined as any portion of unobscured sky visible through the tree canopy. This study utilized light to measure indirectly the density and deflective capacity of three leafy canopies. The measurement of light in its true physical sense was not attempted. 


\section{Methods}

Structural descriptions of the canopies

Profile diagrams of forest transects were constructed according to standard methods described by Davis and Richards (1933) and Richards (1952). One site (containing at least one of the photographic locations) was selected as representative of a mature, undisturbed canopy in each of the three rainforest formations. The locations of the three rainforests and their respective classifications according to Webb $(1959,1968)$ are:

(1) Cool temperate or microphyll fern forest (MFF) at $1400 \mathrm{~m}$ elevation on a slight eastern aspect in the New England National Park $\left(32^{\circ} 30^{\prime} \mathrm{S}\right)$;

(2) Warm temperate or simple notophyll vine forest (SNVF) at $60 \mathrm{~m}$ elevation on the east-sloping bank of a tributary of the Hacking River in the Royal National Park ( $\left.34^{\circ} 10^{\prime} \mathrm{S}\right)$; and

(3) Subtropical or complex notophyll vine forest (CNVF) at $800 \mathrm{~m}$ elevation in the Dorrigo National Park (30 20'S), on the eastern slopes of the New England plateau.
All woody plants greater than $1 \mathrm{~m}$ in height within a $70 \times 8 \mathrm{~m}$ transect were included. Tree heights and canopy depth were calculated with the aid of a hypsometer, and drawn to scale. Canopy depth was defined as the cumulative vertical length intersecting elements of canopy taken from the top of the uppermost canopy down through the lowest-level foliage (Fig 1), and mean canopy depth was calculated from 15 replicate measurements taken at $5 \mathrm{~m}$ intervals along the profile diagrams.

\section{Light measurements}

Direct light readings Light readings were taken in different regions of the canopy using a Lambda quantum meter. Access to the upper canopy was attained using ropes and technical climbing apparatus (Lowman 1982, 1984). In most cases, an emergent tree was climbed in order to reach across to the upper canopy of a neighbouring tree. The same sites were measured under clear, sunny conditions and repeated in cloudy conditions. At least five measurements were taken in each region. Canopy regions were delineated as follows:

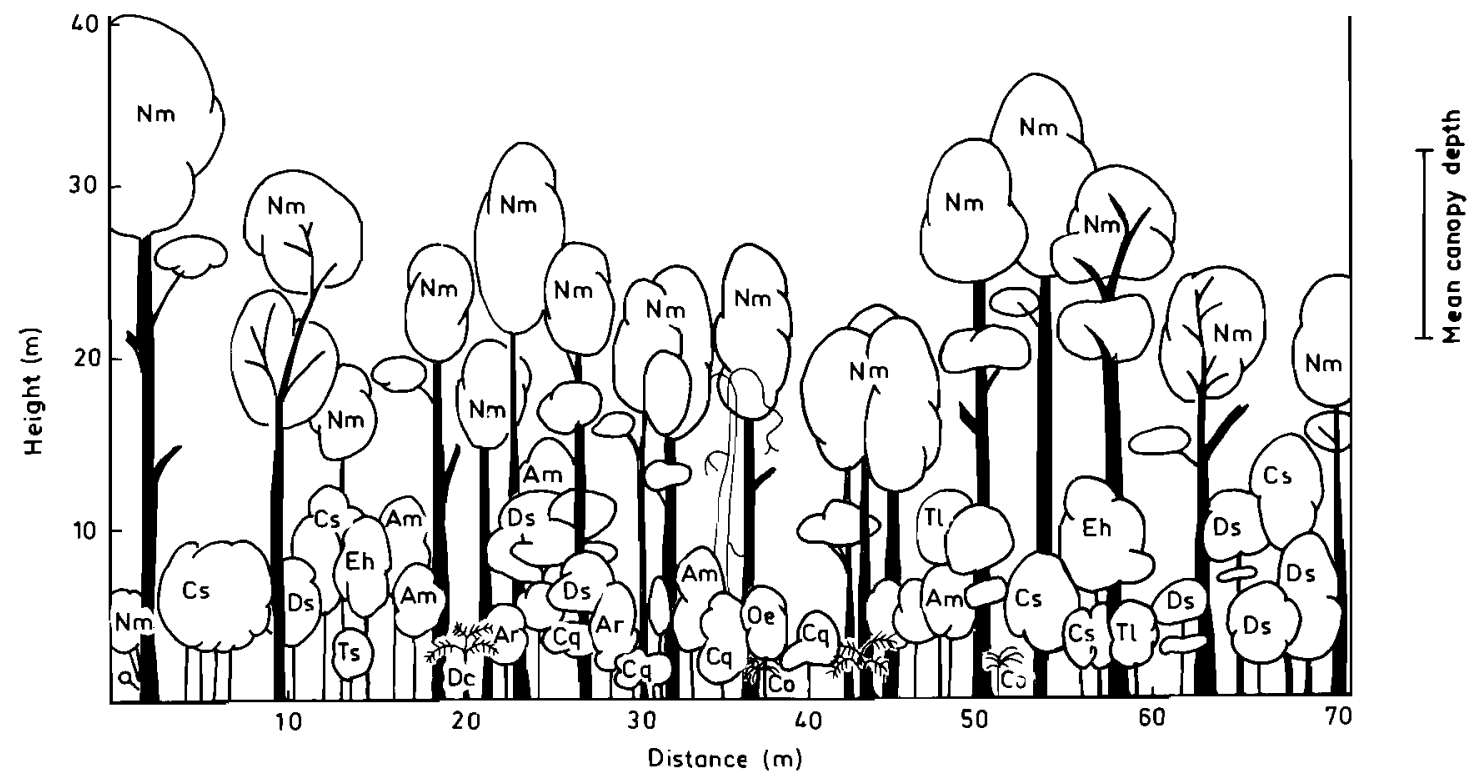

FIG. 1. Profile diagram of a cool temperate rainforest, New England National Park, NSW. Species abbreviations: Am Acacia melanorylon; Ar Alyxia ruscifolia; Co Cordyline siricta; Cq Coprosma quadrifida; Cs Crypiocarya sp.; Da Dicksonia antarctica; Ds Doryphora sassafras; Eh Elaeocarpus holopetalus; $\mathrm{Nm}$ Nothofagus moorei; Oe Orites excelsa; TI Trochocarpa laurina; Ts 
(1) Upper canopy:

Above - over the uppermost canopy leaves; exposed to direct light.

Within - approximately $10 \mathrm{~cm}$ below the uppermost canopy leaves; light diffused with only one leaf layer overhead.

(2) Lower canopy:

Sun fleck - leaf surface within $2 \mathrm{~m}$ of ground level that received a transient beam of direct light.

Shade - leaf surface within $2 \mathrm{~m}$ of ground level that received no direct light.

Gap - area wider than $5 \mathrm{~m}$ on the forest floor with direct light.

Measurement of light through the canopies Hemispherical photography was used in an unorthodox manner to measure relative changes in rainforest canopy structure as indicated by amounts of unobscured sky visible at ground level (Horn 1971). Ten initial light readings were made at random within each forest to determine mean light penetration levels, and three permanent photographic sites were chosen in each forest that best represented mean light levels. Photographs were taken every month for 1 year, at appoximately $1000 \mathrm{~h}$. Because light quantity was not being measured, and instead sky visibility was used as an indicator of canopy leafiness, corrections for zenith and time of year were not necessary (Horn 1971). The spherical photographs were projected onto a horizontal screen to a standard size, and areas of light marked with black ink on acetate sheets. The light was separated into 'sun flecks', defined as any small spherical image of light; and 'gaps', any larger or less symmetrical area of light. An area meter (Lambda Instruments, Model 300) was used to calculate areas of total light, gaps, and sun flecks; and the amounts were expressed as percentages of the area of the circular image. This method does not quantify the physical amount of light reaching the forest floor (since it varies with cloud cover, and position of sun on a daily and seasonal basis), rather, it provides a relative index of canopy cover and density as indicated by light infiltration.

\section{Results}

\section{Structural characteristics of the canopies}

Figures 1-3 illustrate the profile diagrams constructed in representative sites of each rain-

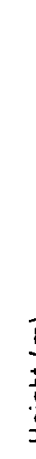

I

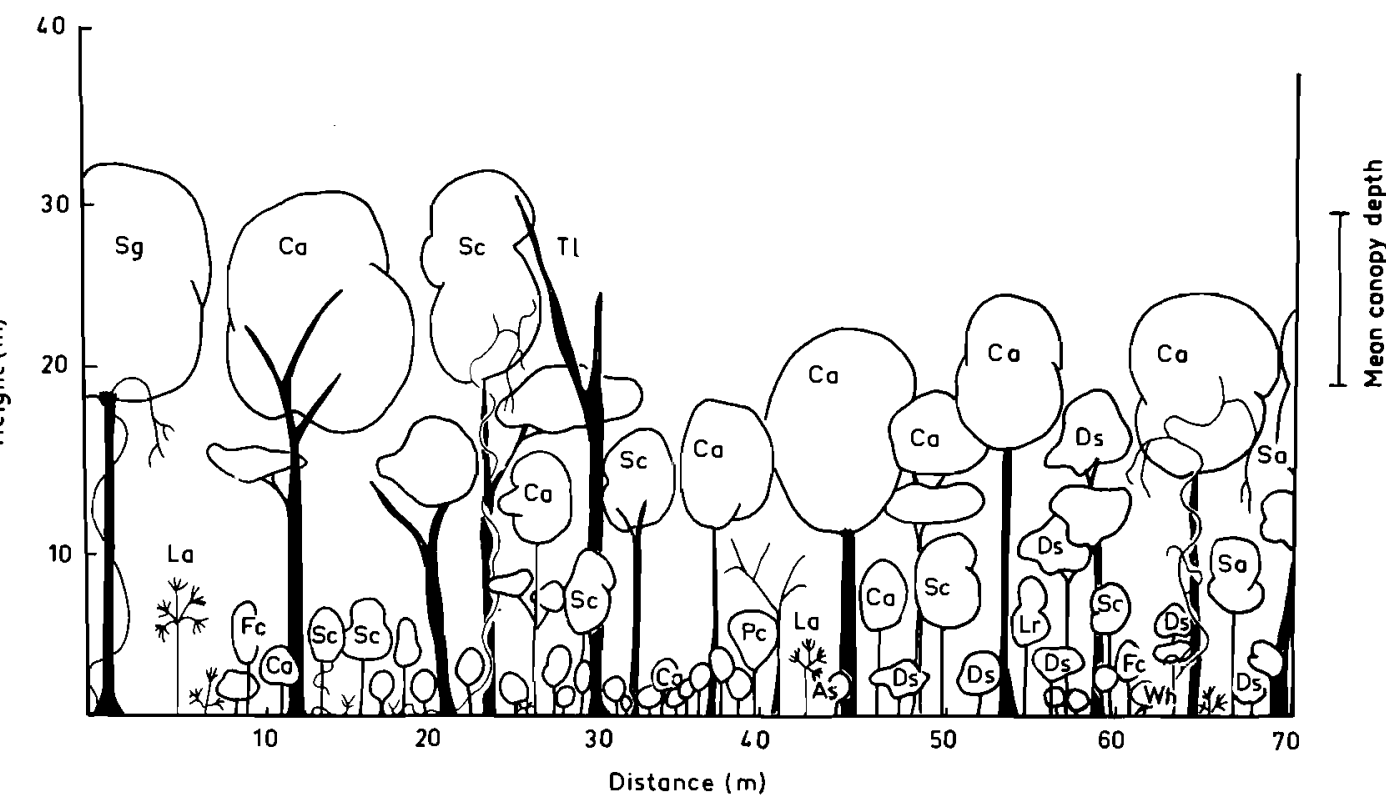

FIG. 2. Profile diagram of a warm temperate rainforest, Royal National Park, NSW. Species abbreviations: As Acmena smithii; Ca Ceratopetalum apetalum: Da Diploglottis australis; Ds Dorvphora sassafras; Fc Ficus coronata; La Livistona australis; Lr Litsea reticulata; $\mathrm{Pc}$ Polvosma cunninghamii; $\mathrm{Pu}$ Pitlosporum undulatum; Sa Sloanea australis; $\mathrm{Sc}$ Sy zygitu coolminianum; $\mathrm{Sg}$ Syncarpia glomulifora; TI Trisiania laurima; Wh Hilekea hucgcliana. Vines: Piper novae-hollandiae; Cissus sterculifolia. 


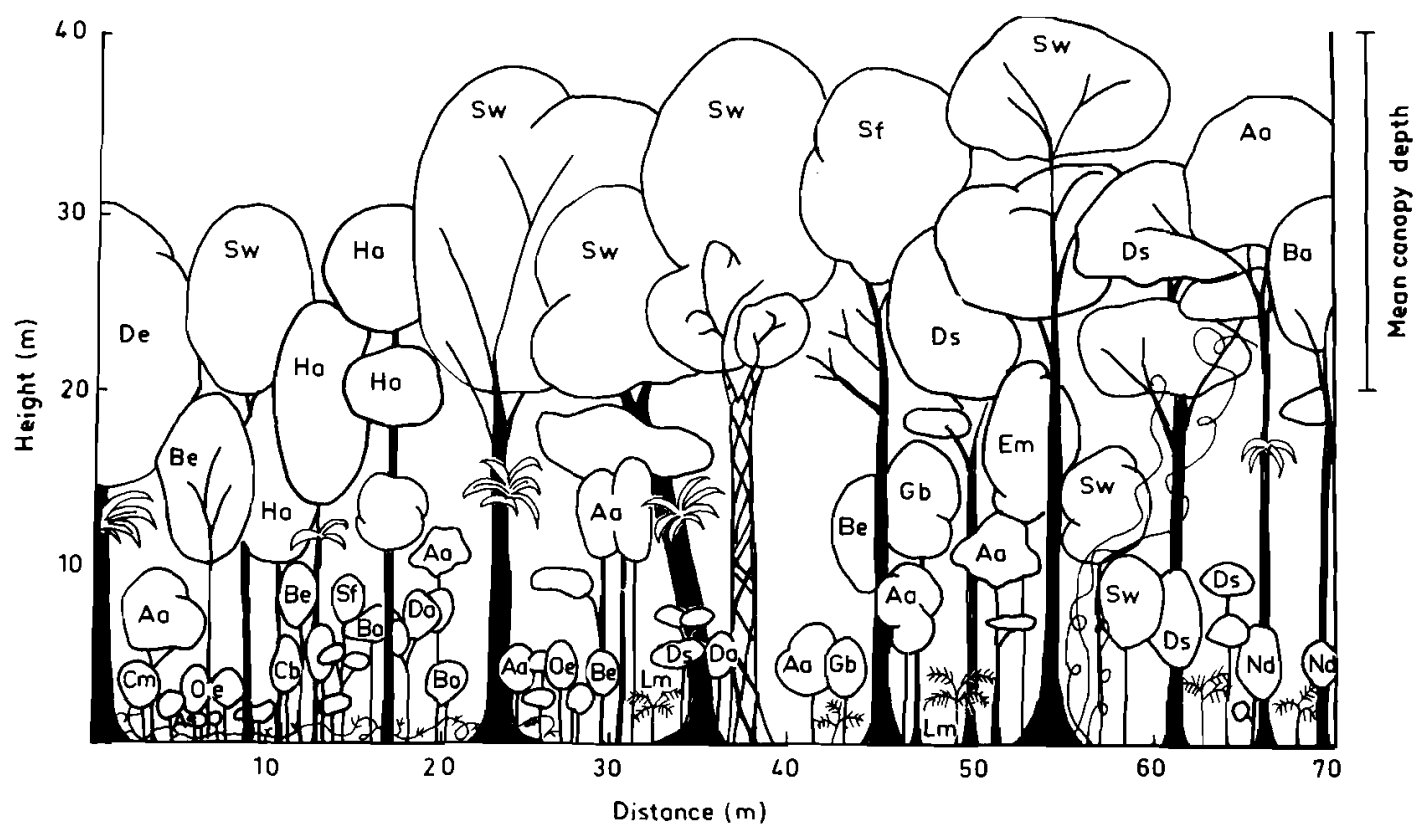

FIG. 3. Profile diagram of a subtropical rainforest, Dorrigo National Park, NSW. Species abbreviations: Aa Alectryon subcinercas; An Asplenium nidus; Be Busistoa euodiiformis; Ba Brachychiton acerifolium; Cm Cryptocarya meissneri; Da Diploglottis australis; De Dendrocnide excelsa; Ds Doryphora sassafras; Em Endiandra muelleri; Fw Ficus watkinsiana; Gb Geissois henthami; $\mathrm{Ha}$ Heritiera actinophylla: Lm Linospadir monostachya, Na Neolitsea deaibata; Oe Orites excelsa; Sf Syzygium francisii; So Schizomeria ovata; Sw Sloanea woollsii. Vines: $\mathrm{Cm}$ Calamus muelleri; vine sp.

forest formation. More detailed information on the sites, including leaf biomass and leaf area indices, is given elsewhere (Lowman 1982).

The canopy of the MFF is dominated by one species, antarctic beech (Nothofagus moorei) with an understorey of 8-10 species including sassafras (Doryphora sassafras), possumwood (Quintinia sieberi), mountain blueberry (Elaeocarpusholopetalus), and mountain laurel (Cryptocarya sp.). The evergreen canopy extends to approximately $30 \mathrm{~m}$ in two layers. The mean canopy depth throughout the site is $12 \mathrm{~m}$.

The SNVF canopy is intermediate in its species diversity between the other two rainforest formations. It displays some structural features similar to CNVF but is simpler in scale. Five to 10 species occur throughout the canopy: coachwood (Ceratopetalum apetalum), sassafras (Doryphora sassafras), maiden's blush (Sloanea australis), lilly pilly (Acmena smithii) and others. The canopy, of average height $30 \mathrm{~m}$, is composed of $1-3$ major leaf layers with an average depth of $10.6 \mathrm{~m}$.
The CNVF is the most diverse rainforest canopy in New South Wales, composed of species such as sassafras (D. sassafras), giant stinging tree (Dendrocnide excelsa), yellow carabeen (Sloanea woolsii), booyong (Argyrodendron actinophyllum), flame tree (Brachychiton acertifolium) and many others. This habitat exhibits many characteristics associated with true tropical rainforest: buttresses, lianes, tree ferns, numerous drip tips, epiphytes, and three or more canopy layers approximately $20 \mathrm{~m}$ in depth and extending up to $40 \mathrm{~m}$.

The CNVF canopy is significantly deeper than the two temperate canopies. The MFF canopy has an obviously higher frequency of gaps, as well as a smaller depth of canopy.

\section{Light levels through the canopies}

Direct light readings The general range of values obtained for light ( $\mu$ Einstein $\mathrm{m}^{-2}$ per s) is listed in Table 1. The amount of light 
TABLE 1. Light measurements ( $\mu$ Einstein $\mathrm{m}^{-1}$ per s) within three Australian rainforest canopies (1000 $\left.\mathrm{h}\right)$

\begin{tabular}{|c|c|c|c|c|c|c|}
\hline \multirow[t]{3}{*}{ Canopy region } & \multicolumn{2}{|c|}{ Subtropical } & \multicolumn{2}{|c|}{ Warm temperate } & \multicolumn{2}{|c|}{ Cool temperate } \\
\hline & Sunny day & Cloudy day & Sunny day & Cloudy day & Sunny day & Cloudy day \\
\hline & \multicolumn{2}{|c|}{ (s.e.m.) } & & & & \\
\hline \multicolumn{7}{|l|}{ Upper canopy } \\
\hline Above & 2000 & $60-80(2.1)$ & 2000 & $60-80$ & 2000 & $60-80$ \\
\hline Within & $100-200(9.2)$ & $20-30(1.5)$ & $100-200$ & $20-30$ & $500-700$ & $30-40$ \\
\hline \multicolumn{7}{|l|}{ Lower canopy } \\
\hline Sun fleck & $800-9000(20.2)$ & $10-20(3.5)$ & $600-800$ & $20-30$ & 1150 & 60 \\
\hline Shade & $10-50(8.3)$ & $5-10(0.3)$ & $10-200$ & $5-20$ & $100-200$ & $8-10$ \\
\hline Gap & - & - & - & - & 1900 & 60 \\
\hline
\end{tabular}

available to a leaf surface decreased dramatically from $2000 \mu$ Einstein $\mathrm{m}^{-2}$ per s above the upper canopy to as low as $5 \mu$ Einstein $\mathrm{m}^{-2}$ per $s$ in the shaded regions of the lower canopy. The magnitude of the difference in light levels between the upper and lower canopy regions was progressively greater as the canopy complexity increased (i.e. from MFF to SNVF to CNVF).

In the understorey, sun flecks represented as much as $50 \%$ of direct sunlight levels whereas shade regions represented less than $1 \%$ of the amount of direct sunlight. Light levels on cloudy days were approximately one-tenth the level on sunny days, although this may vary depending on different types of cloud cover.

\section{Measurement of light through the canopies} The monthly measurements of visible light unobscured by the tree canopies were significantly different among sites (Table 2) but not over time $\left(F_{9,60}=0.46\right.$, NS). A significantly greater percentage of unobscured sky was visible beneath the canopy of MFF than the SNVF or CNVF canopies (Table 2). The monthly fluctuations in skylight appeared to coincide with leaf-fall patterns; however, these changes were much less apparent than hypothesized (Fig. 4). As predicted, the greatest proportion $(\sim 25 \%)$ of light visible on the MFF floor occurred after the autumnal leaffall peak (March-May) and the great amount in the CNVF $(\sim 12 \%)$ occurred just after the spring leaf-fall peak (October-December), although in neither forest was the seasonal variation in visible skylight statistically significant. The SNVF did not show any change in the amount of unobscured sky that correlated with either leaf-fall or leaf emergence patterns. Instead, the slight fluctuations may be due to small scale disturbances (c.g. branch mortality). The branch architectural patterns appeared to maintain stable light interception in the canopy throughout the year, despite seasonal leaf-fall events.

Table 2 summarizes the mean canopy depths and the proportions of sky visible through the three canopies. The CNVF had a significantly decper canopy, and also the least amount of sky visible beneath it. The SNVF canopy was

TABLE 2. Summary of the comparisons of canopy light interception characteristics at three rainforest sites (mean valuc)

\begin{tabular}{|c|c|c|c|c|c|c|c|c|c|}
\hline & Subtropical & & $\begin{array}{l}\text { Warm } \\
\text { temperate }\end{array}$ & & $\begin{array}{l}\text { Cool } \\
\text { temperate }\end{array}$ & s.e.m. & d.f. & $\mathrm{F}$ & $\begin{array}{c}\text { Significance } \\
\qquad(P)\end{array}$ \\
\hline $\begin{array}{l}\text { Total amount of sky visible } \\
\text { through canopy (\% of area of } \\
\text { hemispherical photograph) }\end{array}$ & 10.77 & $=*$ & 11.17 & $<$ & 21.83 & 0.35 & 2,87 & 160.87 & $<0.001$ \\
\hline $\begin{array}{l}\text { Light flccks (\% of total unobscured } \\
\text { sky visiblc below the canopy) }\end{array}$ & 37.8 & $=^{*}$ & 33.2 & $>$ & 22.6 & 1.02 & 2,87 & 99.11 & $<0.001$ \\
\hline $\begin{array}{l}\text { Gaps (\% of total unobscured sky } \\
\text { visible bclow the canopy) }\end{array}$ & 62.2 & $<$ & 66.8 & $<$ & 77.4 & 1.01 & 2,87 & 70.68 & $<0.001$ \\
\hline Ratios of (light fleck : gap) & 60.8 & $=*$ & 49.7 & $>$ & 29.2 & 1.03 & 2,87 & 59.95 & $<0.001$ \\
\hline Canopy depth (m) & 20.03 & $>$ & 10.6 & $=*$ & 12.03 & 0.58 & 2.42 & 26.97 & $<0.001$ \\
\hline
\end{tabular}

*The two means are not significantly different by the Student-Newman-Keul's test. 


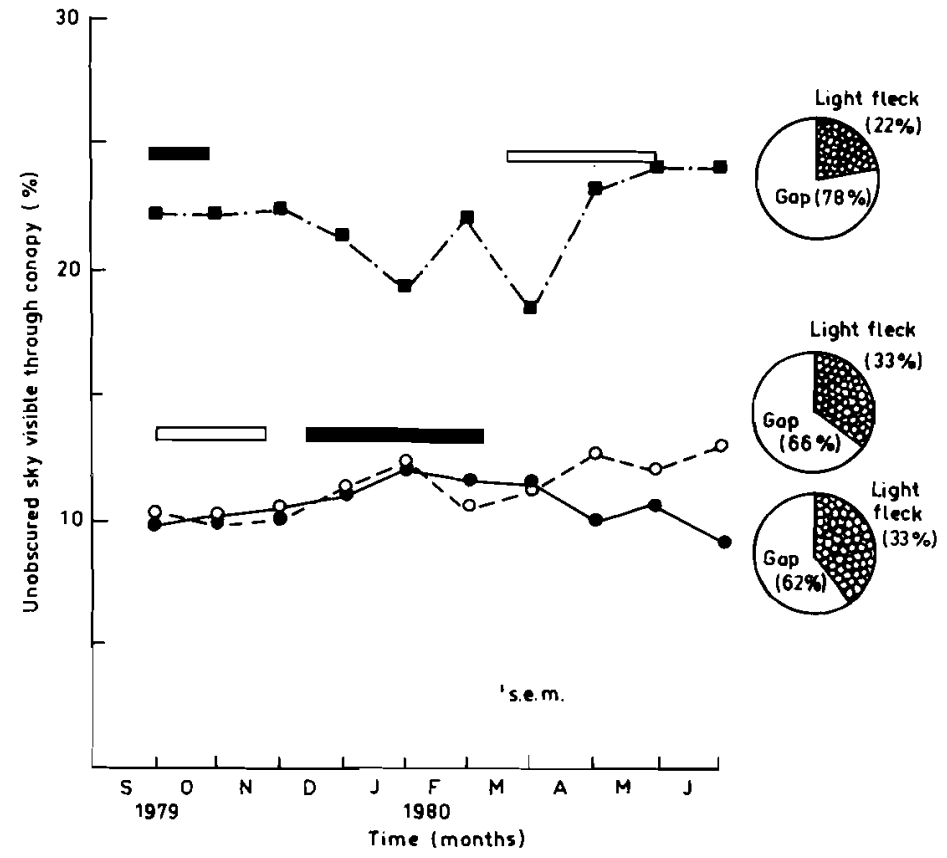

FIG. 4. Mean amount of unobscured sky visible through the canopies of three Australian rainforests as measured from

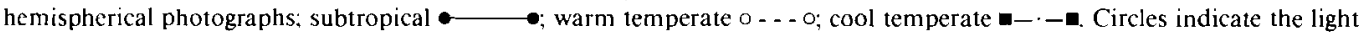
leck:gap proportions. Bars represent main periods of leaf emergence (solid) and leaf-fall (open).

similar to the CNVF canopy in light infiltration except that its canopy was shallower. The MFF canopy had the greatest portion of sky visible through it, and a higher proportion of gaps to sun flecks than the other canopies.

\section{Discussion}

The Australian evergreen rainforests examined did not exhibit significant seasonal changes in the amount of unobscured sky visible through their canopies, despite the fact that up to onehalf of the MFF canopy may be lost during leaffall peaks and the fact that the CNVF includes completely deciduous species (e.g. Brachychiton acerifolius and Toona australis) as scattered canopy trees. The original hypothesis is therefore rejected. An alternative explanation for the year-round constancy of light observed may relate to structural characteristics of the canopy, rather than seasonal growth or senescence patterns of leaves. The deep, multilayered canopy in the CNVF creates an obvious structural barrier to light influx into the lower regions despite intermittent leaf-fall. The SNVF canopy has a relatively shallow depth; but the fact that no more than $12 \%$ of the sky ever remained unobscured at ground level implies that the leaf density is extremely high. Other measurements of leaf area index affirmed this (Lowman 1982). In addition, the spring leaf flush is simultaneous with leaf senescence, so that the canopy is always leafy.

The absence of seasonality in sky visible through the MFF canopy is not as easily explained by the structural features evident in the profile diagrams. Its thinner, less stratified canopy would appear to allow greater visibility of unobscured sky through it during the winter months when half the canopy has fallen; but this was not the case. Subsequent examination of beech branch architecture may instead explain the constant proportions of sky visible through the canopy, despite the seasonal changes of leaf material present. As with other members of the family Fagaceae, the branches and leaves are oriented horizontally in antarctic beech (Halle et al. 1978). When leaf-fall occurs, light penetration to the lower beech canopy may increase, but the horizontal layers of beech leaves intercept light so that the amount of 
unobscured sky seen at ground level is unchanged. Since light levels do not change seasonally under the beech canopy, only the occurrence of gaps by tree falls may allow the continued monopoly of beech in the upper canopy by triggering the release of seedlings and suckers already established in the understorey.

The use of hemispherical photography in this study did not directly measure the light regime. Such photographs can only be used to directly measure the light regime if sufficient information is available on the degree of cloudiness and variation in proportions of diffuse to direct sunlight and daily total solar radiation, as well as seasonal variation in the solar track across the sky (Anderson 1964). The purpose of photography in this study, however, was to compare the seasonal changes in the overall structure of forest canopies as interceptors of skylight, and to relate these to the environment of the understorey (Horn 1971). This investigation showed that not only did the amount of skylight vary between the three rainforests, but also the proportions of gaps to sun flecks. Light was composed mainly of flecks in the CNVF with its dense, deep canopy, while gaps were most frequent in the higher elevation MFF with its thinner, more disturbed canopy. These differences have obvious consequences for regeneration: seedlings appear less limited by light in the MFF where temperature or some other environmental condition is probably the limiting factor. Regrowth is rapid in the gaps of the CNVF where light is probably a major factor required to stimulate regeneration. All three rainforests had relatively low unobscured sky visible through the canopy, and it is well documented that disturbances (i.e. light gaps) are an important mechanism to stimulate regeneration of suppressed seedlings (Connell et al. 1984). These patterns of rainforest regeneration are currently under investigation (Webb et al. 1972; Connell 1978a,b).

These analyses of canopies and light interception emphasize the importance of disturbance and gap formation in the growth dynamics of the rainforest community where light penetration does not change seasonally. Presumably, in the low-light environments of the CNVF and SNVF canopies, there is little opportunity for understorey individuals to be released from a suppressed state unless a canopy gap is created (i.e. a disturbance occurs). Without seasonal changes in light infiltration through the canopy, there is no opportunity for ephemeral growth as in northern temperate, deciduous forests. The MFF canopy has a higher frequency of gaps, the existence of which have two possible explanations. First, due to more rigorous climatic conditions, disturbance may occur more frequently; and second, again due to the rigorous climate, a tree may grow more slowly, therefore taking longer to attain canopy height and to occupy the gaps than in the SNVF and CNVF. Only long-term observations can substantiate either hypothesis.

\section{Acknowledgments}

I wish to thank Dr Peter Myerscough and Professor Harold Heatwole for their helpful criticism of the manuscript; Dr Anthony Underwood for statistical advice; Bert Lester for photographic assistance; Margaret French for field assistance; Sandra Pont for her clerical skills; and Professors Joseph Connell and Peter Ashton for many stimulating discussions on rainforests. This research was funded in part by a Sydney University Postgraduate Studentship and an Australian Museum Grant. The manuscript was completed during the tenure of an Australian Research Grants Scheme grant at the University of New England.

\section{References}

Anderson M. C. (1964) Light relations of terresirial plan1 communities and their measurement. Biol. Rev. 39 , 425-86.

Brasell H. M., Unwin G. L. \& Stocker G. C. (1980) The quantity, temporal distribution, and mineralelement content of litterfall in two forest types at two sites in tropical Australia. J. Ecol. 68, 123-39.

Connell J. H. ( 1978 a) Tropical rain forests and coral reefs as open non-equilibrium systems. In: Population Dynamics: Symposium of the British Ecological Society, London. April 1978 (eds R. M. Anderson, L. R. Taylor and B. Turner) pp. 141-63. Blackwell Scientific Publications, Oxford.

Connell J. H. (1978b) Diversity in tropical rain forests and coral reefs. Science 199, 1302-10.

Connell J.H., Tracey J.G. \& Webb L. J. (1984) Compensatory recruitment, growth and mortality as factors maintaining rain forest tree diversity. Ecol. Monogr. 54, 141-64.

Davis T. W. A. \& Richards P. W. (1933) The vegetation of Moraballi Creek, New Guinea; an ecological study of a limited area of Tropical Rain Forest. Part 1. J. Ecol. 21, 350-84. 
Evans G. C. \& Coombe D. E. (1959) Hemispherical and woodland canopy and the light climate. J. Ecol. 47. 103-13.

Halle F., Oldeman R.A. A. \& Tomlinson P.B. (1978) Tropical Trees and Forests - An Architectural Analysis. Springer-Verlag. New York.

Horn H. (1971) The Adaptive Geometry of Trees. Princeton University Press, Princeton, New Jersey.

Jackson M. T. (1966) Effects of microclimate on spring phenology. Ecologv 47, 407-1 5 .

Lowman M. D. (1982) Leaf growth dvnamics and herbivory in Australian rain forest canopies. PhD thesis, University of Sydney, Sydney.

Lowman M. D. (1984) An assessment of techniques for measuring herbivory; is rainforest defoliation more intense than we thought? Biotropica 16, 264-8.

Richards P. W. (1952) The Tropical Rain Forest. Cambridge University Press, Cambridge.
Webb L.J. (1959) A physiognomic classification of Australian rain forests. $J$. Ecol. 47, 551-70.

Webb L.J. (1968) Environmental relationships of the structural types of Australian rain forest vegetation. Ecologv 49, 296-3ll.

Webb L. J., Tracey J.G. \& Williams W. T. (1972) Regeneration and pattern in the subtropical rain forest. J. Ecol. 60, 675-95.

Webb L. J.. Tracey J. G.. Williams W. T. \& Lance G. N. (1969) The pattern of mineral return in leaf litter of three subtropical Australian forests. Altst. For. 33. $99-110$.

(Final manuscript received November 1985) 